Author's preprint of an article to appear in Critical Discourse Studies 7/4 (November 2010) pp. 263-275. For the published version, see http://www.informaworld.com.

\title{
Stance-taking and public discussion in blogs
}

\section{Greg Myers}

Department of Linguistics and English Language, Lancaster University, Lancaster, United Kingdom

Department of Linguistics and English Language

Lancaster University

Lancaster LA1 4YT

United Kingdom

\begin{abstract}
Blogs, which can be written and read by anyone with a computer and an internet connection, would seem to expand the possibilities for engagement in public sphere debates. And indeed, blogs are full of the kind of vocabulary that suggests intense discussion. But a closer look at the way this vocabulary is used in context suggests that the main concern of writers is self presentation, positioning themselves in a crowded forum, in what has been called stance-taking. When writers mark their stances, for instance by saying $I$ think, they enact different ways of signalling a relation to others, marking disagreement, enacting surprise, and ironicising previous contributions. All these moves are ways of presenting one's own contribution as distinctive, showing one's entitlement to a position. In this paper, I use concordance tools to identify strings that are very frequent in a corpus of blogs, relative to a general corpus of written texts, focus on those relatively frequent words that mark stance, and analyse these markers in context. I argue that the prominence of stance-taking indicates the priority of individual positioning over collective and deliberative discussion.
\end{abstract}

Keywords: blogs, stance, public sphere, irony

Acknowledgements: My thanks to Sofia Lampropoulou, Ruth Wodak, and Lilie Chouliaraki for their comments on this paper.

\section{Introduction}

The cover of a collection of essays, The Uses of Blogs (Bruns \& Jacobs, 2006), shows serried ranks of radio microphones, as if blogs were replacing the one-to-many voice of a mass medium with many voices. ${ }^{1}$ This transformation of the media landscape, with on-line media where users produce as well as consume the content (what Bruns calls 'produsage' (Bruns \& Jacobs, 2006: 6)) has been the focus of a great deal of 
attention and hope from critical media studies. Many media scholars have seen in the rise of press and broadcast media a shift in which 'the classic community of publics is being transformed into a society of masses' (Mills, 1956: 300). As Mills says, much of our understanding of democratic processes depends on the idea of a public or publics:

In a public, as we may understand the term, 1) virtually as many people express opinions as receive them. (2) Public communications are so organized that there is a chance immediately and effectively to answer back any opinion expressed in public. Opinion formed by such discussion (3) readily finds an outlet in effective action, even against - if necessary - the prevailing system of authority. And (4) authoritative institutions do not penetrate the public, which is more or less autonomous in its operations (Mills, 1956: 303-4)

In contrast, in a mass (and in mass media), only a few people get to express opinions, there is limited feedback, the discussions lead to no action, or to carefully channelled actions, and the forums of discussion are controlled by the authorities (see also Habermas, 1991 [1962]: 249). Enthusiasts for blogs have argued they satisfy criterion (3) for a real public, when they bring down a powerful Member of Congress or coordinate a presidential campaign, and the enthusiasts celebrate blogs' independence of government and mainstream media institutions (criterion 4). Whether they are in fact so effective and independent, I will leave to other studies. But they certainly do allow as many people to express opinions as receive them (criterion 1), since almost anyone with an internet connection to read a blog could also write one. And most blogs make it easy to answer back by posting comments (criterion 2). They seem to fit some of the demands for a public sphere (see also Fairclough, 2000; Wodak \& Wright, 2006).

After ten years of blogging, critical media analysts have reason to feel disenchanted. The problems are not to do with the technical affordances of accessibility or feedback, but with the way discussion takes place in this forum. Though anyone can express an opinion, a few well-known blogs get most of the 
attention, and postings from the mass of bloggers come to wider notice only when they are picked out by one of the 'A-list'. Though anyone can respond, comments also lead to flaming, trolling, and threadjacking (turning a discussion to one's own hobbyhorse). Blogs are just as likely to spread unfounded rumours as to give channels for progressive action. And while they are proudly independent of mainstream media, they are not independent of prevailing ideologies and institutionally-organised campaigns.

One component of all these problems is the perceived need in the blogosphere to present oneself as an individual with entitlement to an opinion. I will argue that the bloggers, and commenters on blogs, in my sample are constantly concerned with self presentation, positioning themselves on a crowded terrain of other bloggers and commenters. The emphasis on individual voice and perspective makes for some engaging writing, and it may have its own beneficial political role to play. But it does not have the focus on a shared social project that would be needed for deliberative discussion. It is not the same as participatory citizenship.

In this paper, I would like to look in detail at the act of marking that a statement in a blog or comment is an individual perspective. The linguistic features that particularly interest me are those used in stance-taking ((Biber \& Finegan, 1989; Clift, 2006; DuBois, 2007; Jaffe, 2009). Here is one influential definition of the term stance:

Stance is a public act by a social actor, achieved dialogically through overt communicative means, of simultaneously evaluating objects, positioning subjects, and aligning with other subjects, with respect to any salient dimensions of the sociocultural field (DuBois 2007: 220).

This broad term covers a range of linguistic features that have long been studied separately, such as modality, evaluation, evidentiality, hedging, politeness, or metadiscourse. The advantage of taking them together, following DuBois's definition, 
is that stance-taking focuses our attention of the 'public act' of taking a point of view rather than on one or another specific grammatical or discourse form. So stancetaking does not just involve having an opinion on a topic; it involves using that opinion to align with or disalign with someone else. I have illustrated elsewhere some of the range of stance devices used in blogs (Myers, 2009: Ch. 6). Here I will take a different approach, and start with the particular linguistic items, such as cognitive verbs and a specific use of adverbs, that stand out in my corpus in comparison to a reference corpus. Besides these common stance-marking items, there are ways of stance-taking that are not signalled by any specific linguistic feature, so I will discuss one of the devices - ironic quotation - that is particularly common in blog comments.

\section{Data and Methods}

Bloggers argue about many issues, from bread recipes to cosmology, but I have focused here on discussions of what could be considered public issues. I have broadened the discussion to include the on-line comments (where the blogger enables them) as well as the original posts. Though the bloggers get the attention, public discussion in the blogosphere is as much in the comments as in the blogs. And comments on the more popular blogs give a wider range of participation than do blogs themselves; anyone can post (subject to registration and/or moderation in some cases), and their words will be seen by a much larger number of readers than they would be if each commenter just posted them on their own (mostly ignored) blog. I have chosen five blogs that are current and popular and have many comments:

- Michelle Malkin (http://michellemalkin.com/)and Yglesias

(http://yglesias.thinkprogress.org/) are two well-known US blogs, of the right and left respectively; both are in Technorati's list of the 100 most popular blogs, based on how many other blogs link to them. 
- Bitch PhD (http://bitchphd.blogspot.com/) and Sepia Mutiny

(http://www.sepiamutiny.com/sepia/) both have several writers, and considerable readerships for a more focused range of topics. Bitch $\mathrm{PhD}$ is no longer just about the one eponymous academic; it deals with a range of issues from a feminist perspective. Sepia Mutiny is written by a collective of young people of South Asian origin (they use the term desis) living in the US, on such topics as their social lives, Asian celebrities and businesses, politics, careers, and families.

- Going Underground (http://london-underground.blogspot.com/), an awardwinning blog by Annie Mole, has posts on all sorts of topics relevant in some way to the London transport system, from fashions seen on platforms to movie scenes set in the underground. I include it here because even a special-interest blog takes up public issues, in this case fares and safety.

In all these five blogs, the bloggers post daily and many commenters respond within that day, sometimes writing about the original entry, sometimes about other blogs, and sometimes with no discernable relevance to anything. Typically the threads tend to fray over time, leading on to other discussions, either because of a deliberate deviation from the topic by one commenter, or because of the gradual mutation of one topic into another. For each blog, I started on the same day (23 October 2009) and collected posts and comments until I had more than 10,000 words of that blog. So this half of my sample was about 50,000 words, in a file I named 'allblogs'.

I took the other half of my sample - another 50,000 words, roughly - from a rather different kind of web discussion site. Metafilter (http://www.metafilter.com/) was one of the first popular applications of blogging software, developed by Matthew Haughey in 1999 to enable members to post short comments with links to a front 
page, which are then the starting point for comments by other members. There is a strong sense of community and of a shared project around the discussions on Metafilter. It can be seen as a community of practice (Barton \& Tusting, 2005; Wenger, 1998), for instance in the way new contributors are asked to pass through an apprenticeship, reading and engaging in limited participation to learn the norms of the community before posting a topic for discussion. So the discussions often have a kind of witty and controlled interplay, even when there are fierce and even rude disagreements, and those norms affect the prevailing styles of stance-taking.

To analyse these corpora, I used Wmatrix, a corpus concordance tool developed by Paul Rayson. ${ }^{2}$ A corpus concordance tool gives the frequency of words in the texts, but that frequency is not in itself interesting for our purposes; the most frequent words in a large corpus are likely to be the most frequent words in any sample of English: the, $a$, is and so on. A keyword is a word that is relatively more frequent in this corpus than in a reference corpus to which one is comparing it, so it says something about what is distinctive in this corpus, for instance about blogs in comparison to writing in general. In my study, the reference corpus was a sampler of the written sub-corpora of the British National Corpus (http://www.natcorp.ox.ac.uk/). Wmatrix lists the keywords, not in the order of frequency, but in the order of the statistical significance of their relative over-use, as measured by log likelihood. A log likelihood of over 15.13 (the cut-off I used for consideration in my study) means that the difference is extremely unlikely to be attributable to chance. ${ }^{3}$

Many of the keywords are just what one would expect, because they are the content words associated with the topic discussed, which will not be as common in a larger sample of texts (for instance, Bakerloo in Going Underground, or desi in Sepia Mutiny), or the strings used uniquely on blogs, such as date stamps. Some keywords 
are clearly central to the function of blogs, so central that an analyst might not notice them without the corpus tool to point them out.

I started my analysis with stance markers that occur in the list of keywords, rather than with a broader checklist of features of modality and evaluation, because there is too much danger for a discourse analyst, with blogs especially, of picking out examples to illustrate their point while missing the overall character of the corpus. The examples that stand out in the first qualitative coding of texts are usually those that are unusual and striking in some way. The lure of the neat example is particularly problematic for such a heterogeneous and polyvocal corpus as this oneheterogeneous in that there are many writers, and polyvocal in that each can choose one or more of a range of possible voices, echoing, ironicising, or earnestly affirming.

There are several concordancers that one could use for this analysis; I used Wmatrix because, besides giving word frequencies, it also tags every word for grammatical word class (part of speech), with reasonable accuracy, using the CLAWS probabilistic tagging tool, and it also tags them for semantic groups, using the categories in the UCREL Semantic Analysis System (USAS). The individual keywords are the basis of my argument, but I sometimes use these broader tags to check on the keywords, to find if there were other words used in similar ways, for instance, to go from the use of actually to the wider category of stance adverbs.

Keywords do not tell the whole story, because of course the same string of characters can have several different uses besides stance taking; there are indeed no words or word classes that function solely to mark stance. So the next stage is to take each string marked as a keyword that could be a stance marker and look at it in a concordance, a list of the occurrences of the string with the context on either side, to 
see how they are being used. I think, for instance, can be used in ways that mark stance:

I think ${ }^{4}$ however, that this is often a point of friction in friendship between whites and poc in the US. [Bitch PhD; 'poc' here is 'people of color'] This usage marks stance because the embedded statement ('this is often a point of friction ...') is presented as the point of view of the writer. But I think can also be used in ways that do not mark stance:

I think about black women's hair quite a lot. [Bitch $P h D]$

This is not stance, because think here is used in the sense of having something on one's mind, as in 'Don't think of elephants', not in the sense of taking a stance on something, such as black women's hair. And even when the I think is certainly marking stance, for instance, signalling the degree of commitment of the writer, the effect or marking the statement as a point of view can be to weaken it (it's just my view) or strengthen it (I have a right to my opinion and experience).

These complexities might make it seem impossible for an analyst to tell when someone is taking a stance. But stance-taking is, as DuBois reminds us, a public act, not a private cognitive state (DuBois, 2007), so there should be evidence in the text of what is being signalled and, often, of how the readers interpret those signals in context.

\section{Discussion and stance-taking}

Though I argue that individual stance-taking takes precedence over discussion, I do not deny that discussion is going on. Besides the stance markers I will study, the list of keywords for the 'allblogs' corpus, compared to the BNC Written Sampler, includes because, why, so, bias, question, admit, misleading, connection, and understand. All of these could be (and mostly are, on examination of the 
concordances) words used in arguing and responding to other arguments. If we turn to the most frequent semantic tags in the USAS categories, we find heavy use of such categories as 'Thought and Belief', 'Cause and Effect / Connection', 'If', 'Comparing: Similar/different', 'Evaluation', and 'Negative', all of which are categories used in rhetorical structure (Mann \& Thompson, 1988). But I will not be looking at content of the arguments or their abstract form (for examples of argument construction in computer-mediated communication, see Gurak, Antonijevic, Johnson, Ratliff, \& Reyman, 2004; Wodak \& Wright, 2006). I will focus on the specific words they use to indicate they are taking a stance in a discussion, especially cognitive verbs, stance adverbs, and conversational particles, because they can tell us what sort of discussion these writers signal that they are entering.

\section{Cognitive verbs}

Perhaps the clearest way to mark that a stance is a stance is with a verb of cognition (I think), affect (I feel), or appearance (it seems), followed by a clause complement.

I guess she means we don't own the banks. (Sepia Mutiny)

'We don't own the banks' is a statement about the world. 'She means' attributes this view to his mother. 'I guess' marks all of this as a stance, in this case, something the writer is not entirely certain about. And the stance marker typically comes first (though it does not have to), so it serves as a condition while reading what follows (Biber, Johansson, Leech, Conrad, \& Finegan, 1999: 971). The example sentence would have a different effect if 'I guess' were moved to the end, as an afterthought. Cognitive verbs are salient in my corpus of blogs because they are, apparently, unnecessary: what one writes is what one thinks even if one does not say so. The stance marker makes a public act of taking a stance, and it can show, for instance, the 
kind of subtle gradations of commitment conveyed by I guess, which is not the same as I think or I know.

The list of keywords for the blogs, when compared to the BNC written corpus, includes several cognitive verbs (Table 1).

[Table 1 about here]

This table shows that seven cognitive verbs are much more common in the sample of blogs than one would expect in a sample of written language. Note that this is not the same as saying that they are high in the raw frequency count. Realize, for instance, only occurs twice per thousand words, 14 times in the whole 'allblogs' corpus. But it occurs much less frequently in the BNC, so it is listed as a key word. Understand is somewhat more common in the 'allblogs' corpus, with 26 occurrences, but it is also fairly frequent in the BNC, so it has a lower (but still significant) log likelihood.

The verb that is most salient for my purposes, both in terms of frequency and in terms of keyness, is think. The semantic category 'Thought and Belief', which includes nouns such as attitudes and judgment as well as verbs, has 632 occurrences in the blogs, and think accounts for 215 of them. But as I have noted, think is used in many kinds of discourse acts, and not all these occurrences mark stance. To find out what I think is doing in 'allblogs', we need to look at the concordance. The sample in Figure 1. gives an impression of how stance marking occurs alongside other uses.

[Figure 1 around here]

Nine of the twenty instances shown in this figure are straightforwardly marking the writer's stance:

I don't think all white people have the same hair Four of the instances attribute a stance to someone else:

They think they know what the world is like 
And seven are not, by the definition used here, marking stance at all; they are describing or demanding an act of cognition:

Think before you make any comments

The proportions in this tiny bit of the concordance are typical of the list as a whole; that is, more than half the uses of cognitive verbs are marking the stance of the writer or attributing a stance to someone else.

But what are bloggers and commenters doing by marking stance? As one might expect, some uses soften advice or disagreement:

Sometimes I think a huge part of parenting is learning to live with feeling overwhelmed. Over the years we get more graceful about it: easier on ourselves and our kids. (Bitch PhD)

Mcmama, I think the point isn't that the curiosity itself is racist. (Bitch PhD) In the first of these examples, a commenter advising a harassed parent first says that this view is one she has only some of the time, and then frames it with a cognitive verb so that the general advice is just her opinion. In the second example, I think suggests a clarification, with the implicit suggestion that Mcmama, another commenter, has missed the point of the post.

Because a statement introduced in this way lays no claim to certainty, it can be used in parallel constructions to introduce two contradictory possibilities:

I 'd like to think it was a result of my good looks and charm, but really I think it 's just the power of Bollywood. (Sepia Mutiny) Most examples are in first person, but think can also be used to attribute hypothetical stances that the writer implies cannot be sustainable:

Slap Factory, do you think it's right for news anchors (not opinion, news) to repeatedly advertise one political protest to the exclusion of all others? Do you 
really think that's something you would see on a CNN or MSNBC newscast? (Metafilter)

These are rhetorical questions; it seems unlikely that Slap Factory will respond that they do believe in news anchors advertising a protest. In several of the examples I have quoted (and in 10 of the 215 instances in the concordance), the explicit marking of stance with I think co-occurs with an explicit marking of addressee (Mcmama, Slap Factory). Even where the addressee is not marked, they are there by implication, as potentially holding a different stance.

There are many other verbs (and nouns) to express cognitive processes, but variations like I guess and I believe tend to be used by one writer or in one post. I think is common across the 'allblogs' corpus. It less common in Going Underground and Metafilter, and that is consistent with the difference in tone between those two subcorpora and others in my corpus. Though I think can be used to hedge as well as to strengthen (Kärkkäinen, 2003), as it does in other genres, in the blogs it seems to correlate with more heated adversarial arguments.

\section{Conclusion 1: Cognitive verbs are used mainly to signal a relation to another person or persons, rather than to do their literal task of marking epistemic uncertainty.}

\section{Stance Adverbs}

As I have noted, Wmatrix tags word classes (parts of speech), and one of the most over-used word class tags is that for adverbs (the tag RR, log likelihood 224). It may seem impossible to explain the relative frequency of occurrences of items for such a broad class (Biber \& Finegan, 1988; Tseronis, 2009). But it is worth noting that many of the keywords in this category can function as boosters: totally, really, definitely, absolutely, completely. One might expect the use of boosters in the 
polemical atmosphere of blog discussions, as in this post (about a pay claim made by drivers on the underground):

I would really, really, really like to hear a defence of this, because I just can't think of one. (Going Underground)

But these adverbs have other functions besides boosting. They can be used ( 9 of 100 instances in 'allblogs', 5 of 17 in Metafilter), in one-word phrases, usually before a comma, full stop, or question mark, to suggest a sceptical response to something said earlier:

For instance, can someone think manmade global warming is a serious threat, but still be considered to be in favor of limited government?

Of course. Really. (Malkin)

The passage the commenter quotes is presumably meant as a rhetorical question. Instead of giving what is suggested as the only possible answer, no, the commenter says 'of course'. The 'Really' marks this response as a stance, implying that the opponent might think it was a joke. This kind of response to others accounts for frequent use of really with a question mark, to express doubt or surprise about what was just said:

Really? Name one time conservatives had a protest against the behemoth Medicare expansion. (Malkin)

Walker Percy is from Alabama? Really? godDAMMIT WHERE IS THAT BOURBON. (Metafilter)

The hate for William Tecumseh Sherman, who was frankly a hero

Really? (Metafilter)

Bubble? From the guy who thinks Fox News is only as bad as the other media outlets? Really? (Metafilter) 
These usages do not so much express their skepticism as enact it, as if the writers were taken aback in conversation. This usage is particularly common in Metafilter, where participants prefer very short, witty ripostes.

One particularly over-used adverb, actually, nearly always functions to position a statement as a contrast to some other statement or expectation, particularly when it occurs at the beginning of the sentence (and the comment):

Actually, we don't have a huge problem with moderate Republicans. It's the LIBERAL Republicans we can't stand. (Malkin)

Actually, there are lot of largish metros mysteriously absent here. (Yglesias) Actually, I have to disagree, kmz. It IS necessary to eat sushi. (Metafilter) Actually, this could be pretty useful to set up last-minute after-work happyhour type stuff without having to resort to mass e-mails or text-messages. (Sepia Mutiny)

In the first three examples, the commenter is marking a contrast with what was said in an earlier post. In the last, the contrast is with what the author herself might have thought before about the usefulness of this new social networking site. The contrastive use of actually is a useful device in rhetoric of blog commenters. Like I think, it is apparently and conventionally polite, mitigating possible disagreement. But it also implies the groundlessness of the view to which one is responding. The contrast suggests that what one as to say is worth attention, because one is adding something new and unexpected to the discussion.

Conclusion 2: Adverbs, especially when used at the beginning of a comment, can signal a contrastive relation to previous comments. 


\section{Conversational particles}

It is often observed that various on-line genres use features more associated with speech than writing (Crystal, 2006; Yates, 1996). But this does not mean that bloggers and others are just following the conventions of an on-line register. They could be choosing features appropriate to the interpersonal rhetoric of this genre, and thus using features that are also more likely to be associated with face-to-face communication. For instance, I think is a keyword when the blogs are compared to the BNC Written Sampler, but not when compared to the BNC Spoken sampler. The bloggers are not trying to imitate the sound of speech, but use I think for the interpersonal functions it often has in speech (and has less often in writing).

While blogs are not necessarily like conversation, one set of keywords clearly is drawn from the conversational register: the use of particles such as $o k(\log$ likelihood 32.43), hey (22.40), oh (17.91), and in particular blogs wow and $u h h$. Sometimes the particles occur in reported speech, and they can in fact serve as markers of reported speech when there is no reporting verb, as in this example in which a mother recalls interacting with her toddler daughter during the day:

I get some details out of her ("Hey, have you ever heard of Johan Sebastian Bach?”... ) (Bitch PhD)

The toddler daughter signals the shift to her voice with the kind of particle used in conversation to get attention. Or the reported speech may be attributed as a generic act to a whole class of people:

"ooh, fuzzy" is not racism. (Bitch PhD)

A commenter invokes the whole idea of white people responding to black people's hair with an elongated $o h$ that suggests the kind of naïve, fascinated, and potentially offensive response that has already been discussed in the comments on that post. 
These uses are stance-markers in that they shift the voice from that of the writer as principal to that of a particular or generic person in a conversational setting.

Most often conversational particles are used to mark a response to another comment. They come first in the sentence (and in the comment, usually), in the same position as most cognitive verbs and most adverbs, signaling that there is a stance coming even before we know what it is a stance on.

LD - uhm; we know. (Going Underground)

Um....did anyone notice that chap had NOT ONE WORD TO SAY about the topic of this thread, the bogus 44,000 statistic? (Malkin; it is all in bold font in original)

The uhm in the Going Underground example suggests an oral response to LD that starts with the kind of pause one makes before disagreement, in this case, implying elliptically that regular readers of the blog are well aware of problems with the London Underground. The Malkin example is different, because the commenter is talking to all other readers about a previous comment, but the $u m$ also suggests a hesitation, and thus potential disagreement with a previous turn or comment. A particle can also suggest surprise:

Yes, we were improving after the recession and about to hit another recession, but it still wasn't great. Huh? We weren't improving "after the recession." (Yglesias)

The layers of racism in that sign are amazing. No athletic gear with the exception of University of North Dakota Fighting SIOUX apparel. wow. where to start? (Bitch PhD) 
The enactment of puzzlement or surprise dramatises the kind of response the writer would make if they were responding in speech, in real time. A conversational particle can also be used to interrupt and respond to one's own (ironic) train of thought: everybody knows Hamas is a bunch of terrorist suicide bombers while the Tamil Tigers are freedo...uh...they invented the suicide vest? $\mathbf{u h} . .$. never mind. (Yglesias)

The commenter here is having a fictional dialogue with himself, as he repeats what he says is a common point of view, that Tamil Tigers are freedom fighters, and then responds to what he presents as an interruption from someone adding this new piece of information (the underlined text is a link to a Wikipedia page), and then cancels what he was saying. These examples show that conversational particles are not just thrown in to approximate the sound of a conversational register, they are carefully positioned for rhetorical purposes.

Conclusion 3: Conversational particles can be used to enact disagreement (even disagreement with oneself) by showing hesitation, surprise, or self-interruption as if played out in real-time interaction.

\section{Irony}

So far I have worked from the bottom up, starting with keywords derived by comparing blogs to the BNC Written Sampler, and moving to interpretations of their functions in context, and from there to generalisations about the rhetoric of blogs. But some ways of marking stance do not necessarily have a lexical or syntactic signal: one example is the use of irony. An ironic utterance can be a form of stance-taking because it expresses an opinion that readers are not to take to be that of the writer. To put this in terms of Goffman's participant roles, we take the writer in the role of animator of the views attributed to others, not as the principal expressing their own 
views (Goffman, 1981). In some cases, the writer clearly attributes the ironicised views to someone else:

Yeah, Kafka. It's a shame all those college graduates won't have plum jobs picking lettuce, washing dishes or working in slaughterhouses. (Yglesias) The original post was about unemployment of college graduates, and someone with the pseudonym Kafka had written a comment linking this unemployment to recent legislation offering legal status to undocumented aliens. The writer here points out that many those aliens worked at jobs that are not normally those sought by college graduates. He accomplishes this by setting out a stance that he does not in fact hold 'It's a shame' - and presenting what follows as agreement with Kafka, as if this was what Kafka was saying. The cue to the irony is perhaps the conflict between this list of kinds of employments and the description 'plum jobs'; it is certainly not any one word or construction.

In other cases, there isn't even that kind of signal that the stance stated is to be attributed to someone else:

See if you can spot the commonality in the following statements: I don't want to talk about it anymore; I get SO TIRED of everything being about race. I don't understand what you're telling me; I've never seen that or experienced it so obviously it is your issue alone. IF it's even true. Just because you're (insert race) and (insert experience) happened to you doesn't mean it's because you're (race); I mean, I once (was followed by a security guard) (had my hair touched) (pulled over unfairly) and I'm white so clearly it isn't about race. (Bitch PhD)

All the statements given in reported speech are ways of denying that a particular narrative or phenomenon is an instance of racism. In this case we recognize that the 
writer does not hold these views just because there are so many ways of denying, all lined up. The witty effect arises because we have to do the processing work ourselves to construct the writer's position (before he goes on to make it explicit after this example).

Ironies typically require some knowledge of the ongoing exchange or shared assumptions about the world to be recognized as ironies, especially when they come in very short comments without any apparent cues:

Given the United States' complete failure to investigate possible war crimes, the only hope for justice is an independent, international investigation. (Ygelsias)

He deserves his Nobel at least as much as his two Grammies. (Yglesias) Both examples make up the commenter's whole comment. The first statement asserts something a contributor to or reader of this blog could well believe, and it is recognizable as ironic only because it repeats a sentence from the original post, itself a quotation from a spokesperson for Human Rights Watch, substituting 'Unites States' for 'Sri Lanka'. That then suggests an interpretation undermining the US NGO that made the statement originally. The second statement, a comment on Obama's Nobel Prize, relies on shared frameworks of evaluation. I had originally thought Obama had not won the Grammy award for recordings, so that the cue for the irony was the contrary-to-fact statement. But apparently he has won the Grammy twice. ${ }^{5}$ For readers who know that, the cue for the irony must be the incongruous juxtaposition of a prestigious award for world peace with an award for commercial popular culture products; he did not deserve the Grammies, and now he does not deserve the Nobel. 
Other statements are more obviously attributed. Here, a quotation from an earlier comment (in italics), justifying US actions, is followed by a closely parallel version that is supposedly posted by 'Reynhard Heydrich':

I mean, we've done things that could quite definitely be described as war crimes, but I believe that they were, at times, justified because the people we were fighting had, were currently, and would in the future do way worse than we could on even the ugliest day.

I mean, we Nazis have done things that could quite definitely be described as war crimes, but I believe that they were, at times, justified because the Communist scum we were fighting had, were currently, and would in the future do way worse than we could on even the ugliest day....- Reynhard Heydrich (Metafilter)

The effect of the irony is to suggest that the specious justifications made for the US are so broad that they could be used by even the most notorious war criminal. ${ }^{6}$ It does this not by direct criticism, but by setting up a word-for-word parallelism (and using the rather less subtle cue of the assumed name).

Most of the examples so far involve ironic quotation of a statement made earlier in the discussion. More subtly, the irony can be performed by making statements in a voice attributed to others, even without quotation. Here the shift is gradual:

Oh, and these same people don't want the evil communists pushing evolution, climate change, sex ed or having the President they didn't elect tell their kids to try hard in school, but hey, we should be able to tell women what they do with their reproductive system, teach kids nothing about sex and bring prayer back in schools. I love selective hypocrisy! 
Rant over. As you were. (Sepia Mutiny)

There is a shift from free indirect speech ('evil communists pushing evolution', presumably the words of 'these same people', not the writer) to free direct speech for the contradictory, hypocritical views, with the direct speech signaled by hey. 'I love selective hypocrisy' is complex; the evaluation of these views as 'selective hypocrisy' is apparently that of the writer, while the introduction 'I love' assumes the voice of an imagined person who enjoys such inconsistencies in moral judgments. Finally the whole thing is marked as an excessive expression of opinion: 'Rant over'.

These ironies are common in blog comments; I have coded 50 of them in my sample, and I probably missed a lot. Bloggers resort to ironies because they offer economical ways to distance oneself from other views. The difficulty in processing some of them, figuring out just what is being said, by whom, adds to the wit, particularly when the comments are very short. These comments are not just for show; they do make paraphrasable contributions to the discussion: college graduates do not usually compete for jobs with undocumented aliens, the justification offered for US actions are specious, and the religious right in politics is hypocritical. But what they say is less important than the way they say it. Conclusion 4: Irony dramatises an opposing position to undermine it, and in doing so reinforces the sense that blogs are a field for stance-taking.

\section{Stance-taking in public discussion}

Blogs broaden the terrain of public discussion, potentially allowing anyone with an internet connection to speak to a wider audience, while previously this audience could only be reached by the owners and employees of mass media outlets. And they introduce two way communication, from commenter back to blogger, and from blogger linking to blogger, where before the recipient of a mass media message 
could only write to the editor, or a Member of Congress or other authority (Thelen, 1996). What was perhaps not so well understood, in the early years of enthusiasm for blogs, is how crowded this terrain could become. Bloggers have to compete for any kind of attention, because there are so many other bloggers. The stance-taking that I have analysed in the course of this paper can be understood as a rhetorical response to this crowdedness. Bloggers spend a great deal of rhetorical effort on placing themselves in relation to other bloggers and other possible posts, aligning themselves with some while signalling their own distinctiveness from all.

Analysis of some of the most salient keywords in the corpus of blogs, as compared to a general corpus of written language, shows some of the processes at work in stance-taking:

- Conclusion 1: Cognitive verbs are used mainly to signal a relation to another person or persons, rather than to do their literal task of marking epistemic uncertainty.

- Conclusion 2: Adverbs, especially when used at the beginning of a comment, can signal a contrastive relation to previous comments.

- Conclusion 3: Conversational particles can be used to enact disagreement (even disagreement with oneself) by showing hesitation, surprise, or self-interruption as if played out in real-time interaction.

- Conclusion 4: Irony dramatises an opposing position to undermine it, and in doing so reinforces the sense that blogs are a field for stance-taking.

I have argued that the actual arguments made can become secondary to the elaboration of how one's own position fits in the terrain. This emphasis on the process of stance-taking, rather than the stance itself, is not in necessarily a bad thing. Bloggers are quick to seek out the so far unmentioned detail or link, to reflect on their 
own positions, and to pick out, discuss, and ironicise an emerging phrase. We saw it, for instance, in this example:

See if you can spot the commonality in the following statements: I don't want to talk about it anymore ...

The irony only works if we recognise each of the statements the commenter quotes as the sort of thing people might say, and the wit comes because they are condemned by their own (attributed) words. Most bloggers are constantly aware, maybe too aware, of the huge flow of attention that is the blogosphere.

The problem is that blogs quickly slip from the shared argument to saying 'I'm here'. That assertion can itself be a political act, for instance when the blogger is criticising an authoritarian regime, or bringing to public notice the views of a marginalised group or a buried topic, as when the writers of Sepia Mutiny celebrate the South Asian diaspora in the North America. And the personalisation does bring down to earth, and to everyday lives, some of the issues that in the mass media may become abstract and formulaic.

But the reminder that 'I'm here' does not lead by itself to exploration of differences, critique of accepted ideas, or broadening the range of voices any one citizen encounters. It has often been noted that the self-reinforcing links in blogs lead readers into narrower and narrower views in the great public issues; whatever view I have on an issue, left or right, I am more likely to find much more of it when I log on than I am to find serious challenges to it (Adamic \& Glance, 2005; Kumar, Novak, Raghavan, \& Tomkins, 2004). The emphasis on stance-taking could be similarly limiting, because of its focus on the rhetoric of placing oneself in the field. Argument gives way to a kind of social networking. The image of the phalanx of microphones 
at the beginning of this paper does represent one aspect of blogs, but the problem is not getting one's message out, it is having anyone out there to hear.

Biographical note

Greg Myers is Professor of Rhetoric and Communication at Lancaster University, and author most recently of Matters of Opinion: Talking about Public Issues (Cambridge University Press) and The Discourse of Blogs and Wikis (Continuum). He is currently doing a study with Sofia Lampropoulou of stance in social science research interviews. 


\section{Notes}

1. The concept was by the editors of the book, Joanne Jacobs and Axel Bruns, the photo by Gavin Winter, and the design by Lisa Barfield.

2. Wmatrix can be found at http://ucrel.lancs.ac.uk/wmatrix/; for more information, see Rayson (2008). The best known commercially-available concordancer is Mike Scott's Wordsmith: http://www.lexically.net/wordsmith/. Some users may prefer to use Laurence Anthony's free on-line concordance programme AntConc: http://www.antlab.sci.waseda.ac.jp/software.html.

3. The $\log$ likelihood is the measure of statistical significance preferred by corpus linguists. Paul Rayson gives the following table of equivalents (see http://juilland.comp.lancs.ac.uk/cgibin/wmatrix 2/help.pl\#logl):

$\mathrm{p}<0.05 ;$ critical value $=3.84$

$\mathrm{p}<0.01 ;$ critical value $=6.63$

$\mathrm{p}<0.001 ;$ critical value $=10.83$

$\mathrm{p}<0.0001 ;$ critical value $=15.13$

Since I set the cut-off value for keywords I examined at 15, all the keywords are statistically significant at a high level.

4. In quoted examples, I use underline to show links, italics to show a passage quoted from earlier in the thread, and bold (always added by me unless indicated) to indicate the string I am discussing.

4

5. Obama did win the Grammy award twice, in 2006 and 2008, for audiorecordings of his two books.

6. Heydrich was Gestapo chief, Nazi governor of Bohemia and Moravia, and chair of the Wansee Conference that planned the genocide of Jews and other peoples.

\section{References}

Adamic, L., \& Glance, N. (2005). The Political Blogosphere and the 2004 U.S. Election: Divided They Blog. Paper presented at the International Conference on Knowledge Discovery and Data Mining: Proceedings of the 3rd international workshop on Link discovery, Chicago, Illinois.

Barton, D., \& Tusting, K. (Eds.). (2005). Beyond Communities of Practice. Cambridge: Cambridge University Press.

Biber, D., \& Finegan, E. (1988). Adverbial stance types in English. Discourse Processes, 11 (1-34).

Biber, D., \& Finegan, E. (1989). Styles of stance in English: Lexical and grammatical marking of evidentiality and affect. Text, 9 (1), 93-124.

Biber, D., Johansson, S., Leech, G., Conrad, S., \& Finegan, E. (1999). Longman Grammar of Spoken and Written English. London: Longman.

Bruns, A., \& Jacobs, J. (Eds.). (2006). Uses of Blogs. New York: Peter Lang.

Clift, R. (2006). Indexing stance: reported speech as an interactional evidential. Journal of Sociolinguistics, 10(5), 569-595.

Crystal, D. (2006). Language and the Internet (Second ed.). Cambridge, UK: Cambridge University Press.

DuBois, J. (2007). The stance triangle. In R. Englebretson (Ed.), Stancetaking in Discourse: Subjectivity, Evaluation, Interaction. Amsterdam: Benjamins.

Fairclough, N. (2000). Dialogue in the public sphere. In S. Sarangi \& M. Coulthard (Eds.), Discourse and Social Life (pp. 170-184). Harlow, UK: Pearson Education.

Goffman, E. (1981). Forms of Talk. Oxford: Basil Blackwell.

Gurak, L. J., Antonijevic, S., Johnson, L., Ratliff, C., \& Reyman, J. (Eds.). (2004). Into the Blogosphere: Rhetoric, Community, and Culture of Weblogs: http://blog.lib.umn.edu/blogosphere/. 
Habermas, J. (1991 [1962]). The Structural Transformation of the Public Sphere: An Inquiry into a Category of Bourgeois Society (T. Burger \& F. Lawrence, Trans.). Cambridge, MA: MIT Press.

Jaffe, A. (Ed.). (2009). Stance: Sociolinguistic Perspectives. Oxford: Oxford University Press.

Kärkkäinen, E. (2003). Epistemic stance in English conversation: A description of its interactional functions, with a focus on 'I think'. Amsterdam: John Benjamins.

Kumar, R., Novak, J., Raghavan, P., \& Tomkins, A. (2004). Structure and evolution of blogspace. Communications of the ACM, 47(12), 35-39.

Mann, W. C., \& Thompson, S. A. (1988). Rhetorical Structure Theory: Toward a functional theory of text organization. Text, 8(3), 243-281.

Mills, C. W. (1956). The Power Elite. New York: Oxford University Press. Myers, G. (2009). Discourse of Blogs and Wikis. London: Continuum.

Rayson, P. (2008). From key words to key semantic domains. International Journal of Corpus Linguistics., 13(4), 519-549.

Thelen, D. (1996). Becoming Citizens in the Age of Television. Chicago: University of Chicago Press.

Tseronis, A. (2009). Qualifying standpoints: Stance adverbs as a presentational device for managing the burden of proof. Leiden University, Leiden.

Wenger, E. (1998). Communities of Practice: Learning, Meaning, and Identity. Cambridge: Cambridge University Press.

Wodak, R., \& Wright, S. (2006). The European Union in cyberspace: Multilingual democratic participation in a virtual public sphere? Jounral of Language and Politics, 5(2), 251-275.

Yates, J. (1996). Oral and written aspects of computer conferencing. In S. Herring (Ed.), Computer-Mediated Communication: Linguistic, Social, and CrossCultural Perspectives (pp. 29-47). Amsterdam: John Benjamins. 